\title{
On the Utilization of Nanofluids as Secondary Fluid for Heat Transfer in a Magnetocaloric Cooler
}

\author{
Adriana Greco ${ }^{1}$, Ciro Aprea ${ }^{2}$, Angelo Maiorino², Claudia Masselli²* \\ ${ }^{1}$ DII, University of Naples "Federico II", P.le Tecchio 80, Napoli 80125, Italy \\ ${ }^{2}$ DIIn, University of Salerno, Via Giovanni Paolo II, 132 Fisciano (SA) 84084, Italy
}

Corresponding author. E-mail: cmasselli@unisa.it

https://doi.org/10.18280/ti-ijes.630107

Received: 26 January 2019

Accepted: 20 March 2019

\section{Keywords:}

nanofluids, magnetic refrigeration, magnetocaloric, AMR, heat transfer fluid, $\mathrm{CuO}$

\begin{abstract}
Magnetocaloric refrigeration is based on solid-state refrigerants exhibiting magnetocaloric effect, detected in a temperature change of the materials due to the adiabatic variation of the intensity of a magnetic field applied to it. Magnetocaloric refrigeration could represent potentially an alternative to vapor compression since the former is more environmentallyfriendly. The reference thermodynamical cycle is AMR cycle, applied to a solid-state structure made by the magnetocaloric material, placed between a cold and a hot heat exchanger and subjected to alternative magnetization/demagnetization cycles. To vehiculate the fluxes between cold and hot heat exchangers, a heat-transfer fluid is used: it usually is water or a water-ethylene mixture for sub-zero applications, but innovative solutions could be adopted, such as nanofluids in order to enhance the thermal conductivity of the resulting fluid. In this paper we report the results of an investigation conducted on a parallel-plate AMR refrigerator, employing nanofluids $\left(\mathrm{Al}_{2} \mathrm{O}_{3}\right.$ and $\left.\mathrm{CuO}\right)$ as heat-transfer medium. The analysis was perpetuated changing both the nanofluid volume concentration and the magnetocaloric material. The results are reported in terms of cooling power and coefficients-of-performance and we detect that the effect of using a waterbased nanofluid is always positive in terms of the energy performances of the AMR refrigerator.
\end{abstract}

\section{INTRODUCTION}

As a result of climate change, population growth, and rising expectations regarding quality of life, energy requirements for cooling processes are growing much faster worldwide than for heating [1]. Unfortunately, one of the problems regarding the today-cooling systems is that most coolants cause environmental and health damage since refrigeration is usually based on a vapor compression cycle, which was using CFCs (ChloroFluoroCarbons) as refrigerants. In 1973 these refrigerants were officially classified as toxic for the environment because they were the cause of two major problems: destroying the ozone layer and increasing the greenhouse effect. Therefore, the production of CFCs has had to be abandoned after an international agreement was signed in Montreal in 1987 prohibiting their use [2]. Indeed, the HFCs (HydroFluoroCarbons) were introduced as vapor compression refrigerants, but they are due of significant warming potential causing serious global warming problems to our planet. New research has started to develop alternative strategies to substitute conventional refrigeration with the aim of having zero impact on the environment [3-5].

A class of cooling techniques that could represent potentially an alternative to vapor compression is caloric refrigeration [6-7]. It embraces all the system based on solidstate refrigerants exhibiting caloric effect: an intrinsic property of ferro-caloric materials to change their temperature depending on the application of an external driving field whose intensity varies adiabatically. Among them, there is magnetocaloric refrigeration, a new emerging technology that is based on the MagnetoCaloric Effect (MCE), that can be used to create new thermodynamic cycles for refrigeration purposes [8]. Specifically, variable magnetic fields applied to a magnetocaloric material give rise to magnetocaloric effect (MCE) where an adiabatic magnetization heats up the materials; an adiabatic demagnetization cools it down [9].

The major advantage of magnetic refrigeration devices is that they are more environmentally-friendly than the usual refrigeration devices used until now [10]. These devices are more ecological for different reasons, first of all because of their modest irreversible nature of the transformations that form the thermodynamic cycle. Furthermore, the fluid-state refrigerants used in compression cycles can be replaced by solid-state magnetocaloric materials, eliminating the problems linked to pollution and waste disposal.

The reference thermodynamical cycle of a magnetic cooler is called Active Magnetocaloric Regenerative refrigeration (AMR) cycle and it is Brayton-based [11]. The cycle is applied to a solid-state structure made by the magnetocaloric material which is both refrigerant and regenerator. The structure is placed between a cold and a hot heat exchanger and it is subjected to alternative magnetization and demagnetization cycles. To vehiculate the fluxes between the hot and the cold heat exchangers a Heat Transfer Fluid (HTF) is used.

AMR cycle is composed of four phases:

1) the solid-state magnetocaloric refrigerant is magnetized adiabatically, therefore it heats up following the MCE; 
2) the heat is exchanged with the environment using the secondary fluid that crosses the magnetocaloric regenerator from the cold to the hot side;

3 ) the refrigerant is then demagnetized adiabatically, causing a drop of temperature due to magnetocaloric effect;

4) the cooled down refrigerant absorbs heat from the secondary fluid that crosses it from the hot to the cold side. Therefore, the fluid reaches the cold side (connected to the environment to be refrigerated), colder than its medium temperature. Consequently, the fluid subtracts heat from the cold environment, and it realizes the desired effect of the AMR cycle. Generally, the secondary heat-transfer fluid is water or a water-ethylene mixture for sub-zero applications, but innovative solutions could be adopted, such as nanofluids [12]. Nanofluids are suspensions consisting of solid highthermal-conductivity nanoparticles $(1-100 \mathrm{~nm})$ dispersed in a base fluid to enhance the thermal conductivity of the resulting fluid. The conception of nanofluid, formulated by dispersing metallic or non-metallic nanometer-size particles in base liquids such as water and ethylene glycol, was proposed first by Choi [13] in 1995 and, a few years later, Choi et al. [14] showed that the addition of a small amount (less than $1 \%$ by volume) of nanoparticles to conventional heat transfer liquids increased the thermal conductivity of the fluid up to approximately two times. Ever since, there have been great research-interests in exploring the effectiveness and feasibility of using nanofluids as convective HTF. As a matter of fact, nanofluids are potential HTF with enhanced thermophysical properties and heat transfer performances. Consequently, numerous are the application to which the nanofluid usage is addressed, such as domestic refrigeration, solar cooling, heat exchangers, cooling of transformer oils, and so on [15]. The idea reported in the present paper is to employ nanofluids as HTF for magnetic cooling applications. Up to now, only two inherent studies were published [16-17]. Indeed, this is an extremely forefront study.

In this paper we report the results of an investigation conducted on a parallel-plate AMR refrigerator, employing nanofluids as heat transfer medium. The results were carried out utilizing a 2-D model solved with finite element method. Two different nanofluids $\left(\mathrm{Al}_{2} \mathrm{O}_{3}\right.$ and $\left.\mathrm{CuO}\right)$ were tested in both cases while the AMR employs: the benchmark Gadolinium; a first order $\mathrm{LaFeCoSi}$ material belonging to lanthanum-based alloys. The final aim of the investigation is the evaluation of the energy performances of the AMR working is such cases.

\section{TOOL AND MATERIALS FOR THE INVESTIGATION}

\subsection{The 2-D model}

The 2-D tool modelling the AMR refrigerator was already introduced [18-19] and validated [20-22] in previous investigations. Following are reported briefly the key points, mandatory to understand how it works. The AMR is modeled as a parallel-plate regenerator made of 54 slices of caloric material, separated by channels in which the HTF flows, and it connects a cold and a hot heat exchanger coupled, respectively, with the cold and the hot environment. The model bases on the following mathematical structure:

$$
\begin{aligned}
& \int \frac{\partial u}{\partial x}+\frac{\partial v}{\partial y}=0 \\
& \frac{\partial u}{\partial t}+u \frac{\partial u}{\partial x}+v \frac{\partial u}{\partial y}=-\frac{1}{\rho_{n f}} \frac{\partial p}{\partial x}+v\left(\frac{\partial^{2} u}{\partial x^{2}}+\frac{\partial^{2} u}{\partial y^{2}}\right) \\
& \left\{\frac{\partial v}{\partial t}+u \frac{\partial v}{\partial x}+v \frac{\partial v}{\partial y}=-\frac{1}{\rho_{n f}} \frac{\partial p}{\partial y}+v\left(\frac{\partial^{2} v}{\partial x^{2}}+\frac{\partial^{2} v}{\partial y^{2}}\right)\right. \\
& \frac{\partial T_{n f}}{\partial t}+u \frac{\partial T_{n f}}{\partial x}+v \frac{\partial T_{n f}}{\partial y}=\frac{k_{f}}{\rho_{n f} C_{n f}}\left(\frac{\partial^{2} T_{n f}}{\partial x^{2}}+\frac{\partial^{2} T_{n f}}{\partial y^{2}}\right) \\
& \frac{\partial T_{S}}{\partial t}=\frac{k_{S}}{\rho_{S} C_{S}}\left(\frac{\partial^{2} T_{S}}{\partial x^{2}}+\frac{\partial^{2} T_{S}}{\partial y^{2}}\right) \\
& \left\{\begin{array}{c}
\rho_{n f} C_{n f} \frac{\partial T_{n f}}{\partial t}=k_{n f}\left(\frac{\partial^{2} T_{n f}}{\partial x^{2}}+\frac{\partial^{2} T_{n f}}{\partial y^{2}}\right) \\
\rho_{s} C_{s} \frac{\partial T_{s}}{\partial t}=k_{s}\left(\frac{\partial^{2} T_{s}}{\partial x^{2}}+\frac{\partial^{2} T_{s}}{\partial y^{2}}\right)+Q
\end{array}\right. \\
& Q=Q\left(H, T_{S}\right)=\frac{\rho_{S} C_{S}\left(H, T_{S}\right) \Delta T_{a d}\left(H, T_{S}\right)}{\tau}
\end{aligned}
$$

Equations system (1) models the fluid-flow processes of the AMR cycle; Eq (2) describes the magnetization and demagnetization phases. The influence of the magnetocaloric effect is modeled through the Q-term reported in Eq (3). It converts the magnetocaloric effect into a power density. Since $\mathrm{Q}$ is a function of the field and the temperature, its mathematical expression has been obtained by a mathematical finder software, as a result of elaboration and manipulation of experimental data of $\mathrm{C}_{\mathrm{s}}\left(\mathrm{H}, \mathrm{T}_{\mathrm{s}}\right)$ and $\Delta \mathrm{T}_{\mathrm{ad}}(\mathrm{H}$, $\mathrm{T}_{\mathrm{s}}$ ), coming from scientific literature. For each magnetocaloric-materials there are specific Q-terms corresponding to their magnetization and demagnetization phases.

The model is solved with Finite Element Method and the AMR cycle runs cyclically several times until reaching steady-state conditions.

\subsection{The solid-state magnetocaloric refrigerants}

Magnetocaloric effect consists in a coupling between the entropy of the magnetocaloric material and the variation of an external magnetic field applied to the material, which causes magnetic ordering in the material structure. MCE manifests its highest point in the immediate vicinity of magnetic transition temperatures (Curie point). The two possible magnetic phase-changes that one can observe at the Curie point are First Order Magnetic Transition (FOMT) and Second Order Magnetic Transition (SOMT). At the Curie point a magnetic transition has FOMT characteristics when the material exhibits a discontinuity in the first derivative of the Gibbs free energy (G.f.e.), magnetization function. Dually, it has a SOMT behavior when the gap is detected in the second derivative of G.f.e., magnetic susceptibility, while its first derivative is a continuous function. Aprea et al. in a previous work [23] focused the attention on FOMT and SOMT materials. The investigation introduced in this paper is carried out considering two different magnetocaloric materials: a SOMT (Gd) and a FOMT (LaFeCoSi alloy) one.

Gadolinium (Gd) has been always considered the benchmark material of such technique. Belonging to the lanthanide group, gadolinium is a rare-earth element which exhibits a second order paramagnetic to ferromagnetic transition at the Curie temperature of $294 \mathrm{~K}$ [24]. $\mathrm{LaFe}_{11.05} \mathrm{Co}_{0.94} \mathrm{Si}_{1.01}$ [25], belonging to the rare-earth transition-metals $\mathrm{La}\left(\mathrm{Fe}_{\mathrm{x}} \mathrm{Si}_{1-\mathrm{x}}\right)_{13}$, was considered because of the large MCE exhibiting around room temperature. The 
main advantages of employing $\mathrm{La}\left(\mathrm{Fe}_{\mathrm{x}} \mathrm{Si}_{1-\mathrm{x}}\right)_{13}$ alloys are the cheapness, readily availability and easiness of preparing. Such class of materials presents a first-order itinerant electron metamagnetic transition which produces a giant magnetocaloric effect. Table 1 lists the main features of the above introduced magnetocaloric materials: the temperature at which the transition is manifesting, the peak value of the adiabatic temperature change in correspondence of a magnetic field variation $\Delta \mathrm{H}=[0 ; 1.5] \mathrm{T}$, the density and the thermal conductivity of the materials.

Table 1. Features of the selected magnetocaloric materials

\begin{tabular}{ccccc}
\hline $\begin{array}{c}\text { Magnetocaloric } \\
\text { Material }\end{array}$ & $\begin{array}{c}\mathrm{T}_{\text {Curie }} \\
{[\mathrm{K}]}\end{array}$ & $\begin{array}{c}\Delta \mathrm{T}_{\text {ad,peak }} \\
{[\mathrm{K}]}\end{array}$ & $\begin{array}{c}\rho \\
{\left[\mathrm{kg} / \mathrm{m}^{3}\right]}\end{array}$ & $\begin{array}{c}\mathrm{k} \\
{[\mathrm{W} / \mathrm{mK}]}\end{array}$ \\
\hline $\mathrm{Gd}$ & 294 & 6 & 7900 & 10.9 \\
\hline $\mathrm{LaFe}_{11.05 \mathrm{Co} 0.94 \mathrm{Si}_{1.01}}$ & 287 & 5.5 & 7290 & 8.9 \\
\hline
\end{tabular}

\subsection{The nanofluids}

The nanofluids employed as heat transfer fluid of the AMR refrigerator under investigation are based on two electrically-insulated nanoparticles: $\mathrm{Al}_{2} \mathrm{O}_{3}$ and $\mathrm{CuO}$. Therefore, the alumina-water and the $\mathrm{CuO}$-water nanofluid have been considered. The considered nanofluids are composed of water, as base fluid, in which nanometric particles of alumina $\left(\mathrm{Al}_{2} \mathrm{O}_{3}\right)$ or $\mathrm{CuO}$ were dispersed [26]. Moreover, to conduct the investigation with nanofluids containing variable volume fraction of alumina, we considered different concentrations of nanoparticles dispersed on equal volume of base fluid as:

$\varphi=\frac{V_{n p}}{V_{n f}}=\frac{m_{n p}}{m_{n f}}$

The thermophysical properties of the alumina-water nanofluids are dependent on the volume fraction of nanofluids $\varphi$; therefore, to include such dependence in our caloric heat-pump model, we adopted the following correlations published in previous investigations [27]:

$\rho_{n f}=\frac{m_{n f}}{V_{n f}}=\frac{m_{b f}+m_{n p}}{V_{n f}}=\rho_{b f} \frac{V_{b f}}{V_{n f}}+\rho_{n p} \frac{V_{n p}}{V_{n f}}=(1-\varphi) \rho_{b f}+$

$+\varphi \rho_{n p}$

$C_{n f}=(1-\varphi) C_{b f}+\varphi C_{n p}$

$k_{n f}=k_{b f} \frac{k_{n p}+2 k_{b f}-2 \varphi\left(k_{b f}-k_{n p}\right)}{k_{n p}+2 k_{b f}+\varphi\left(k_{b f}-k_{n p}\right)}$

$\mu_{n f}=\mu_{b f}(1+7.74 \varphi)$

Table 2. Thermophysical properties of the base fluid and the nanoparticles of the two nanofluid under investigation

\begin{tabular}{lcccc}
\hline Substance & $\mathbf{P}\left[\frac{\mathrm{kg}}{\mathrm{m}^{3}}\right]$ & $\mathbf{C}\left[\frac{\mathrm{J}}{\mathrm{kgK}}\right]$ & $\mathbf{K}\left[\frac{\mathrm{W}}{\mathrm{mK}}\right]$ & $\mathbf{M}\left[\frac{\mathrm{kg}}{\mathrm{m}}\right]$ \\
\hline Water & 998.2 & 4182 & 0.597 & $9.93 * 10^{-4}$ \\
$\mathrm{Al}_{2} \mathrm{O}_{3}$ & 3970 & 765 & 36 & - \\
$\mathrm{CuO}$ & 6310 & 550.5 & 32.9 & \\
\hline
\end{tabular}

Table 2 lists the properties of the base fluid and the nanoparticles of the two nanofluids at $\mathrm{T}=293 \mathrm{~K}$ and $\mathrm{p}=1 \mathrm{~atm}$. Table 3 and 4 report, respectively, the thermophysical properties of the $\mathrm{Al}_{2} \mathrm{O}_{3}$-water and $\mathrm{CuO}$-water nanofluids considered as a function of the volume concentration.

Table 3. Thermophysical properties of alumina-water based nanofluids as a function of the concentration of nanoparticles

\begin{tabular}{ccccc}
\hline $\begin{array}{c}\mathbf{A l}_{2} \mathbf{O}_{3} \text {-water nanofluid } \\
\boldsymbol{\varphi}\end{array}$ & $\begin{array}{c}\boldsymbol{\rho}_{\mathbf{n f}} \\
{\left[\frac{\boldsymbol{k g}}{\boldsymbol{m}^{3}}\right]}\end{array}$ & $\begin{array}{c}\mathbf{C}_{\mathbf{n f}} \\
{\left[\frac{\boldsymbol{J}}{\boldsymbol{k g K}}\right]}\end{array}$ & $\begin{array}{c}\mathbf{k}_{\mathbf{n f}} \\
{\left[\frac{\boldsymbol{W}}{\boldsymbol{m K}}\right]}\end{array}$ & $\begin{array}{c}\boldsymbol{\mu}_{\mathbf{n f}} \\
{\left[\frac{\boldsymbol{g} \boldsymbol{m s}}{\boldsymbol{m} \boldsymbol{s}}\right]}\end{array}$ \\
\hline 0.00 & 998.2 & 4182 & 0.597 & $9.93^{*} 10^{-4}$ \\
0.02 & 1058 & 4114 & 0.632 & $11.5^{*} 10^{-4}$ \\
0.04 & 1117 & 4045 & 0.668 & $13.0^{*} 10^{-4}$ \\
0.06 & 1177 & 3977 & 0.705 & $14.5^{*} 10^{-4}$ \\
0.08 & 1236 & 3909 & 0.745 & $16.1^{*} 10^{-4}$ \\
0.10 & 1295 & 3840 & 0.785 & $17.6^{*} 10^{-4}$ \\
\hline
\end{tabular}

Table 4. Thermophysical properties of $\mathrm{CuO}$-water based nanofluids as a function of the concentration of nanoparticles

\begin{tabular}{|c|c|c|c|c|}
\hline $\begin{array}{c}\text { CuO-water nanofluid } \\
\varphi\end{array}$ & {$\left[\begin{array}{l}\rho \mathrm{nf} \\
\frac{\mathrm{kg}}{\mathrm{m}^{3}}\end{array}\right]$} & {$\left[\begin{array}{c}\mathrm{C}_{\mathrm{nf}} \\
{\left[\frac{J}{\mathrm{kgK}}\right.}\end{array}\right]$} & $\begin{array}{c}\mathrm{k}_{\mathrm{nf}} \\
{\left[\frac{W}{m K}\right]}\end{array}$ & {$\left[\begin{array}{l}\mu_{\mathrm{nf}} \\
{\left[\frac{\mathrm{kg}}{\mathrm{ms}}\right.}\end{array}\right]$} \\
\hline 0.00 & 998.2 & 4182 & 0.597 & $9.93 * 10^{-4}$ \\
\hline 0.02 & 1104 & 4109 & 0.632 & $11.5 * 10^{-4}$ \\
\hline 0.04 & 1211 & 4037 & 0.668 & $13.0 * 10^{-4}$ \\
\hline 0.06 & 1317 & 3964 & 0.705 & $14.5 * 10^{-4}$ \\
\hline 0.08 & 1423 & 3891 & 0.744 & $16.1 * 10^{-4}$ \\
\hline 0.10 & 1529 & 3819 & 0.784 & $17.6^{*} 10^{-4}$ \\
\hline
\end{tabular}

\section{THE INVESTIGATION}

The AMR refrigerator was tested in four combination of solid-state refrigerant + heat-transfer fluid:

1) $\mathrm{Gd}+\mathrm{Al}_{2} \mathrm{O}_{3}$-water nanofluid;

2) $\mathrm{Gd}+\mathrm{CuO}$-water nanofluid;

3) $\mathrm{LaFe}_{11.05} \mathrm{Co}_{0.94} \mathrm{Si}_{1.01}+\mathrm{Al}_{2} \mathrm{O}_{3}$-water nanofluid;

4) $\mathrm{LaFe}_{11.05} \mathrm{Co}_{0.94} \mathrm{Si}_{1.01}+\mathrm{CuO}$-water nanofluid.

The model was simulated in a wide range of working conditions: for the above-listed combinations of magnetocaloric + nanofluid material the energy performances were carried out for variable nanofluid concentration of nanoparticles $\varphi=[0 ; 0.02 ; 0.04 ; 0.06 ; 0.08 ; 0.10]$. Moreover, the nanofluid velocity was varied $\mathrm{v}=[0.1 ; 0.2 ; 0.3] \mathrm{m} \mathrm{s}^{-1}$; whereas the frequency of the cycle was kept constant at 1.25 $\mathrm{Hz}$. For the test $\mathrm{Gd}+\mathrm{Al}_{2} \mathrm{O}_{3}$-water nanofluid, the considered temperature ranges were $292 \div 300 \mathrm{~K}$ and $287 \div 295 \mathrm{~K}$ so to study the importance of embracing Curie point in the considered temperature range: indeed, in this case, only one of the two temperature ranges tested includes it.

\section{THE ENERGY PERFORMANCES}

The results are reported in terms of cooling power, that measures the power at which the system subtract heat from the cold environment and Coefficient Of Performance (COP) defined, respectively, as:

$\dot{Q}_{r e f}=\frac{1}{\theta} \int_{3 \tau+n \theta}^{4 \tau+n \theta} \dot{m}_{n f} C_{n f}\left(T_{C}-T_{n f}(0, y, t)\right) d t$

$C O P=\frac{\dot{Q}_{r e f}}{\dot{W}_{T O T}}$ 
COP is the coefficient of performance of the AMR refrigerator and it is conceived as the ratio between the cooling power and the total energy expense made to get it. $\dot{W}_{\text {TOT }}$ embraces both the contributions due to the magnetic field variation and to the mechanical power required for the fluid motion.

Figure 1 reports the trends of the cooling powers for the four tested combinations of caloric materials + HTF, as a function the concentration of the nanofluids. The tests in which gadolinium is the solid-state refrigerant confer globally the highest cooling powers. Furthermore, in the latter case the employment of nanofluids as HTF takes to increasing $\dot{Q}_{r e f}$ in correspondence of growing nanofluid concentration. By the way, if the AMR works with Gd as magnetocaloric refrigerant, the effect of adding $\mathrm{CuO}$ particles in water translates into powers higher than the addition of $\mathrm{Al}_{2} \mathrm{O}_{3}$.

If the AMR refrigerator works with $\mathrm{LaFe}_{11.05} \mathrm{Co}_{0.94} \mathrm{Si}_{1.01}$, the cooling power collected are approximately halved, compared to the ones given by Gd tests. Moreover, one can observe that $\dot{Q}_{\text {ref }}$ has a slight maximum in correspondence of $\varphi=0.06$. This could be attributed to the influence of the increasing dynamic viscosity (with $\varphi$ ) that prevails over the modest solid-fluid heat exchanger given by a magnetocaloric effect smaller than the Gd one.

Since from Figure 1 we observed that $\mathrm{Gd}+\mathrm{Al}_{2} \mathrm{O}_{3}$-water nanofluid is one of the two best combinations, we tested it varying the nanofluid velocity and for $\varphi$ belonging to [0.0; $0.10]$ range and we reported the corresponding cooling powers in Figure 2. The figure shows growing cooling powers both with nanofluid velocity and concentration increasing. If the nanofluids flows with $0.3 \mathrm{~m} . \mathrm{s}^{-1}$ as velocity, in a working range $T_{C} \div T_{H}=292 \div 300 \mathrm{~K}$, the AMR refrigerator touches $140 \mathrm{~W}$ of cooling power in the case $\mathrm{Gd}+10 \% \mathrm{Al}_{2} \mathrm{O}_{3}$ $90 \%$ water.

Figure 3 reports the cooling powers vs nanofluid concentrations for the combination $\mathrm{Gd}+\mathrm{Al}_{2} \mathrm{O}_{3}$-water nanofluids in two different temperature ranges. These results are provided to remark the importance of centering the Curie point of the magnetocaloric refrigerant in the temperature working range. As a matter of fact, the cooling powers registered in the $292 \div 300 \mathrm{~K}$ temperature range are approximately the double of the $287 \div 295 \mathrm{~K}$ one.

Figure 4 reports the trends of the coefficients of performances for the four tested combinations of caloric materials + HTF, as a function the concentration of the nanofluids. The observed trends are the same of the ones shown in figure 1: the tests with gadolinium are the ones to which the greatest COPs are attributed, with maximum COP of 8.7 for the AMR working with $\mathrm{Gd}+10 \% \mathrm{CuO}-90 \%$ water nanofluid $\left(292 \div 300 \mathrm{~K}\right.$; v $\left.=0.2 \mathrm{~m} . \mathrm{s}^{-1}\right)$.

In Figure 5 are reported the COPs evaluated testing the combination $\mathrm{Gd}+\mathrm{Al}_{2} \mathrm{O}_{3}$-water nanofluid varying the nanofluid velocity $[0.1 ; 0.3] \mathrm{m} . \mathrm{s}^{-1}$ and $\varphi$ in $[0.0 ; 0.10]$. As for the corresponding cooling power reported in figure 2 , one can observe growing coefficients of performance with increasing both velocity and concentration of the nanofluid.

Figure 6 shows the coefficients of performances of the AMR refrigerator working with $\mathrm{Gd}$ as solid-state refrigerant and $\mathrm{Al}_{2} \mathrm{O}_{3}$-water nanofluid as heat-transfer medium, in the $292 \div 300 \mathrm{~K}$ and $287 \div 295 \mathrm{~K}$ temperature ranges. As expected, COPs carried out while the AMR was working in $292 \div 300 \mathrm{~K}$ are higher than $287 \div 295 \mathrm{~K}$.

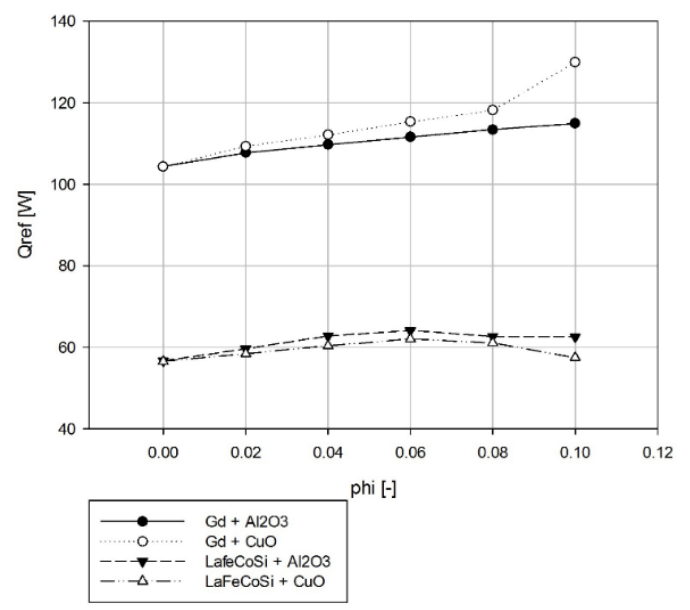

Figure 1. Cooling power vs nanofluid concentration for the four tested combinations of caloric materials $+\mathrm{HTF}$

$\mathrm{Gd}+\mathrm{Al} 2 \mathrm{O} 3 \mathrm{Tc}-\mathrm{TH}=292-300 \mathrm{~K}$

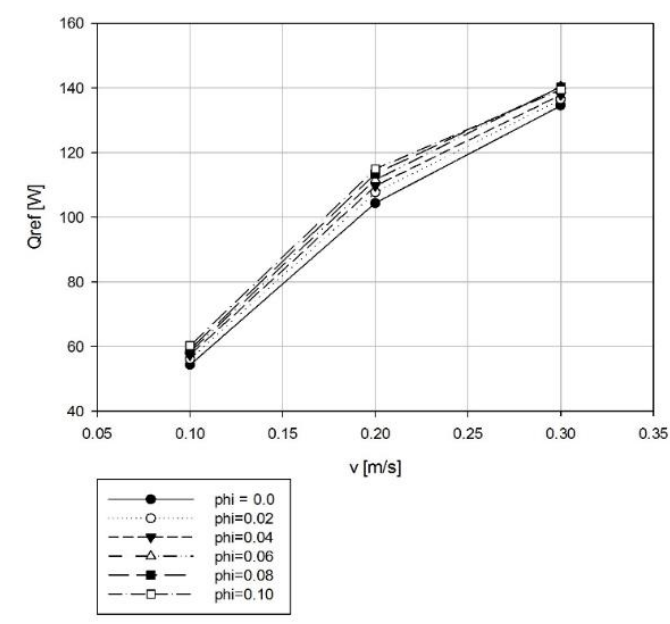

Figure 2. Cooling power vs nanofluid velocity for different concentrations of $\mathrm{Al}_{2} \mathrm{O}_{3}$-water nanofluids

$\mathrm{Gd}+\mathrm{Al} 2 \mathrm{O} 3 \mathrm{v}=0.2$

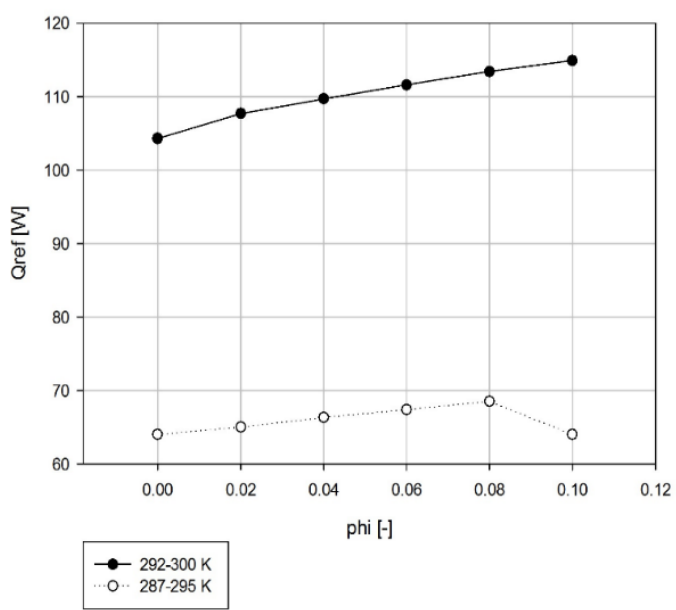

Figure 3. Cooling power vs nanofluid concentrations for the combination $\mathrm{Gd}+\mathrm{Al}_{2} \mathrm{O}_{3}$-water nanofluids in two different temperature ranges 


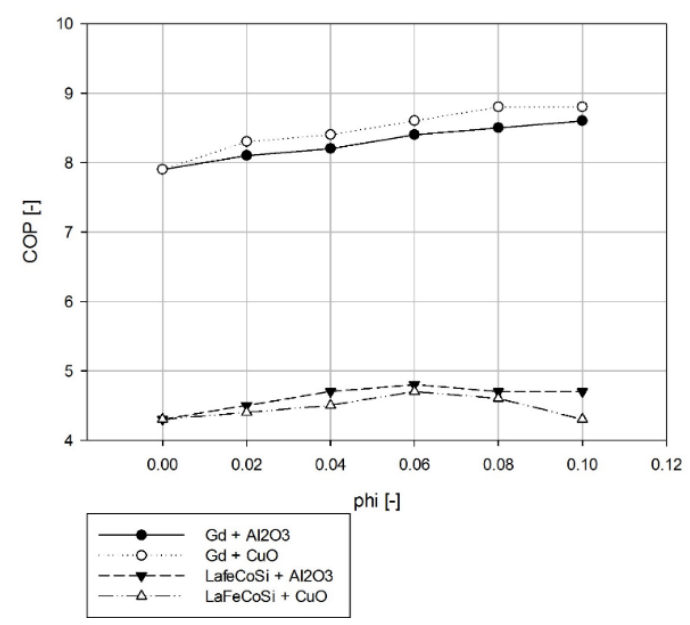

Figure 4. Coefficients of performance vs nanofluid concentration for the four tested caloric materials + HTF combinations

$\mathrm{Gd}+\mathrm{Al} 2 \mathrm{O} 3 \mathrm{Tc}-\mathrm{TH}=292-300 \mathrm{~K}$

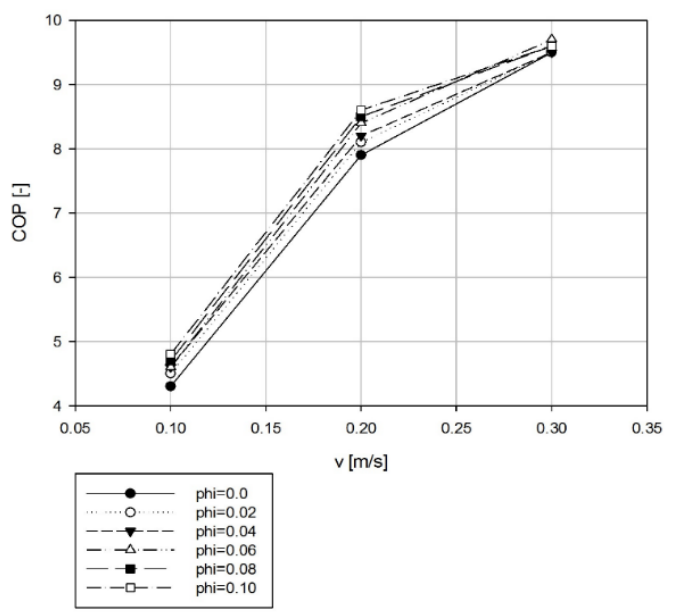

Figure 5. Coefficients of performance vs nanofluid velocity for different concentrations of $\mathrm{Al}_{2} \mathrm{O}_{3}$-water nanofluids

$\mathrm{Gd}+\mathrm{Al} 2 \mathrm{O} 3 \mathrm{v}=0.2$

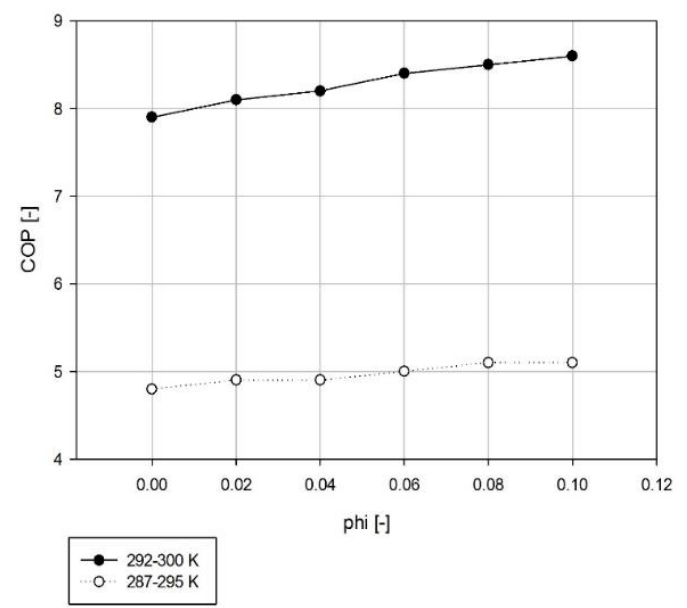

Figure 6. Coefficients of performance vs nanofluid concentrations for the combination $\mathrm{Gd}+\mathrm{Al}_{2} \mathrm{O}_{3}$-water nanofluids in two different temperature ranges

\section{CONCLUSIONS}

In this paper we investigated, numerically, the energy performances of an Active Magnetocaloric Regenerative refrigerator employing water-based nanofluids $\left(\mathrm{Al}_{2} \mathrm{O}_{3}\right.$ and $\mathrm{CuO}$ ) as heat-transfer fluid. The analysis was perpetuated changing both the nanofluid volume concentration and the magnetocaloric material ( $\mathrm{Gd}$ or $\mathrm{LaFe}_{11.05} \mathrm{Co}_{0.94} \mathrm{Si}_{1.01}$ ).

The investigation was performed in a wide set of operating conditions, since the velocity and the concentration of the nanofluids as well as the operating temperature ranges were varied. Basing on the tests performed we observed that the best results both in terms of cooling power and coefficient of performance are given by gadolinium as magnetocaloric refrigerant. The effect of using a water-based nanofluid is always positive in terms of energy performances. Specifically, the addition of $\mathrm{CuO}$ nanoparticles results in $\dot{Q}_{\text {ref }}$ and COP higher than working with only water as HTF and slightly greater than working with $\mathrm{Al}_{2} \mathrm{O}_{3}$-water nanofluid, whom is also satisfying.

In conclusion, basing on the presented investigation, we can assert that the employment of nanofluids as heat transfer fluid of an Active Magnetocaloric Regenerator enhances the energy performances both in terms of cooling power and coefficient of performance.

\section{REFERENCES}

[1] Mirandola A, Lorenzini, E. (2016). Energy, environment and climate: From the past to the future. Int. J. of Heat and Technology 34(2): 159-164. https://doi.org/10.18280/ijht.340201

[2] United Nation Environment Program (UN). (1987). Montreal Protocol on substances that deplete the ozone layer, United Nation Environment Program (UN), New York, NY, USA.

[3] Heath EA. (2017). Amendment to the Montreal protocol on substances that deplete the ozone layer (Kigali amendment). International Legal Materials 56(1): 193205. https://doi.org/10.1017/ilm.2016.2

[4] Aprea C, Greco A, Maiorino A, Masselli C. (2018). The drop-in of HFC134a with HFO1234ze in a household refrigerator. Int. J. of Thermal Sciences 127: 117-125. https://doi.org/10.1016/j.ijthermalsci.2018.01.026

[5] Aprea C, Greco A, Maiorino A, Masselli C, Metallo A. (2016). HFO1234yf as a drop-in replacement for R134a in domestic refrigerators: a life cycle climate performance analysis. International Journal of Heat and Technology 34(2):

S212-S218. https://doi.org/10.18280/ijht.34S2

[6] Aprea C, Greco A, Maiorino A, Masselli C. (2018). Solid-state refrigeration: A comparison of the energy performances of caloric materials operating in an active caloric regenerator. Energy 165: 439-455. https://doi.org/10.1016/j.energy. 2018.09.114

[7] Kitanovski A, Plaznik U, Tomc U, Poredoš A. (2015). Present and future caloric refrigeration and heat-pump technologies. Int. J. of Refrig. 57: 288-298. https://doi.org/10.1016/j.ijrefrig.2015.06.008

[8] Yu BF, Gao Q, Zhang B, Meng XZ, Chen Z. (2003). Review on research of room temperature magnetic refrigeration. International Journal of Refrigeration 26(6): 622-636. https://doi.org/10.1016/S0140- 
7007(03)00048-3

[9] Pecharsky VK, Gschneidner Jr KA. (1999). Magnetocaloric effect and magnetic refrigeration. Journal of Magnetism and Magnetic Materials 200(1-3): 44-56. https://doi.org/10.1016/S0304-8853(99)00397-2

[10] Aprea C, Greco A, Maiorino A, Masselli C. (2018). The environmental impact of solid-state materials working in an active caloric refrigerator compared to a vapor compression cooler. International Journal of Heat and Technology 36(4): 1155-1162. https://doi.org/10.18280/ijht.360401

[11] Gómez JR, Garcia RF, Catoira ADM, Gómez MR. (2013). Magnetocaloric effect: A review of the thermodynamic cycles in magnetic refrigeration. Renewable and Sustainable Energy Reviews 17: 74-82. https://doi.org/10.1016/j.rser.2012.09.027

[12] Yu W, France DM, Routbort JL, Choi SU. (2008). Review and comparison of nanofluid thermal conductivity and heat transfer enhancements. Heat $\begin{array}{lll}\text { Transf. } & \text { Eng. } & \text { 29(5): }\end{array}$ https://doi.org/10.1080/01457630701850851

[13] Choi SUS. (1995). Enhancing thermal conductivity of fluids with nanoparticles. Developments and Applications of Non-Newtonian Flows, FED 231/MD 66: 99-105.

[14] Choi SUS, Zhang ZG, Yu W, Lockwood FE, Grulke EA. (2001). Anomalously thermal conductivity enhancement in nanotube suspensions. Appl. Phys. Lett. 79: 2252-2254. https://doi.org/10.1063/1.1408272

[15] Saidur R, Leong KY, Mohammad H. (2011). A review on applications and challenges of nanofluids. Ren. and sust. En. Rev. 15(3): 1646-1668. https://doi.org/10.1016/j.rser.2010.11.035

[16] Chiba Y. (2017). Enhancements of thermal performances of an active magnetic refrigeration device based on nanofluids. Mechanics 23(1): 31-38. https://doi.org/10.5755/j01.mech.23.1.13452

[17] Mugica I, Roy S, Poncet S, Bouchard J, Nesreddine H. (2017). Exergy analysis of a parallel-plate active magnetic regenerator with nanofluids. Entropy 19(9): 464. https://doi.org/10.3390/e19090464

[18] Aprea C, Cardillo G, Greco A, Maiorino A, Masselli C. (2015). A comparison between experimental and 2D numerical results of a packed-bed active magnetic regenerator. Appl. Therm. Eng. 90: 376-383. https://doi.org/10.1016/j.applthermaleng.2015.07.020

[19] Aprea C, Greco A, Maiorino A, Masselli C. (2015). A comparison between rare earth and transition metals working as magnetic materials in an AMR refrigerator in the room temperature range. Appl. Therm. Eng. 91: 767-777.

https://doi.org/10.1016/j.applthermaleng.2015.08.083

[20] Aprea C, Cardillo G, Greco A, Maiorino A, Masselli C. (2016). A rotary permanent magnet magnetic refrigerator based on AMR cycle. Appl. Therm. Eng. 101: 699-703. https://doi.org/10.1016/j.applthermaleng.2016.01.097

[21] Aprea C, Greco A, Maiorino A, Masselli C. (2017). Analyzing the energetic performances of AMR regenerator working with different magnetocaloric materials: Investigations and viewpoints. Int. J. of Heat and Tech. 35: S383-S390. https://doi.org/10.18280/ijht.35Sp0152

[22] Aprea C, Greco A, Maiorino A, Masselli C. (2018).
Energy performances and numerical investigation of solid-state magnetocaloric materials used as refrigerant in an active magnetic regenerator. Therm. Sc. and Eng. Progr. 6 : 370-379. https://doi.org/10.1016/j.tsep.2018.01.006

[23] Aprea C, Greco A, Maiorino A. (2013). The use of the first and of the second order phase magnetic transition alloys for an AMR refrigerator at room temperature: A numerical analysis of the energy performances. Energy Conversion and Management 70: 40-55. https://doi.org/10.1016/j.enconman.2013.02.006

[24] Dan'kov SY, Tishin AM, Pecharsky VK, Gschneidner Jr KA. (1998). Magnetic phase transitions and the magneto-thermal properties of gadolinium. Phys Rev. B 57(6): $3478-3490$ https://doi.org/10.1103/PhysRevB.57.3478

[25] Bjørk R, Bahl CRH, Katter M. (2010). Magnetocaloric properties of LaFe13-x-yCoxSiy and commercial grade Gd. J. Magn. Magn. Mater. 322(24): 3882-3888. https://doi.org/10.1016/j.jmmm.2010.08.013

[26] Vajjha RS, Das DK, Namburu PK. (2010). Numerical study of fluid dynamic and heat transfer performance of $\mathrm{Al}_{2} \mathrm{O}_{3}$ and $\mathrm{CuO}$ nanofluids in the flat tubes of a radiator. International Journal of Heat and Fluid Flow 31(4): 613-621. https://doi.org/10.1016/j.ijheatfluidflow.2010.02.016

[27] Bianco V, Vafai K, Manca O, Nardini S. (2015). Heat transfer enhancement with nanofluids. CRC Press. https://doi.org/10.1201/b18324

\section{NOMENCLATURE}

\section{Roman symbols}

$\mathrm{C}$
$\mathrm{H}$

$\mathrm{k}$

$\mathrm{m}$

$\mathrm{m}^{\cdot}$

$\mathrm{p}$

$\mathrm{Q}$

$\mathrm{Q}^{\circ}$

$\mathrm{T}$

$\mathrm{t}$

$\mathrm{u}$

V

$\mathrm{V}$

W

$\mathrm{x}$

\section{Greek symbols}

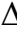

$\theta$

$\mu$

$\checkmark$

$\varphi$

$\rho$

$\tau$

$\Delta$

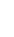

specific heat, $\mathrm{J}^{\mathrm{kg}} \mathrm{kg}^{-1} \cdot \mathrm{K}^{-1}$

magnetic field, A. $\mathrm{m}^{-1}$

thermal conductivity, W. $\mathrm{m}^{-1} \cdot \mathrm{K}^{-1}$

mass, $\mathrm{kg}$

mass rate, $\mathrm{kg} \mathrm{s}^{-1}$

pressure, atm

power density, W. $\mathrm{m}^{-3}$

power, $\mathrm{W}$

temperature, $\mathrm{K}$

time, $s$

longitudinal fluid velocity, $\mathrm{m} . \mathrm{s}^{-1}$

volume, $\mathrm{m}^{3}$

orthogonal fluid velocity, m. $\mathrm{s}^{-1}$

mechanical power, $\mathrm{W}$

longitudinal spatial coordinate, $\mathrm{m}$

orthogonal spatial coordinate, $\mathrm{m}$ finite difference

period of AMR cycle, $\mathrm{s}$

dynamic viscosity, $\mathrm{kg} \cdot \mathrm{m}^{-1} \cdot \mathrm{s}^{-1}$

cinematic viscosity, $\mathrm{m}^{+2}$. $\mathrm{s}^{-1}$

nanofluid concentration

density, kg. $\mathrm{m}^{-3}$

period of each step of AMR cycle, $s$ 


\section{Subscripts}

ad

bf

C

$\mathrm{H}$

nf

$\mathrm{np}$ adiabatic

base fluid

cold

hot

nanofluid

nanoparticles constant pressure

solid

total

TOT 